\title{
The Design of the Medical Intelligent Dustbin
}

\author{
XuChunlei ${ }^{1, a}$ \\ ${ }^{1}$ School of Electrical and Electric Engineering, North China Electric Power University, Beijing, \\ 102206, China \\ axuchunlei961016@163.com
}

Keywords: Intelligent Dustbin, CMOS Camera Tracking,PID, Wireless Communication

\begin{abstract}
Nowadays, stationary dustbinis unable to meet the needs of movement disorder patients. This paper describes a kind of medical intelligent dustbin.After the patient in a hospital bed press the button, the dustbin can reach the specified location steadily and swiftly along the presupposed routine. The lid of the dustbin is opened automatically. And then the dustbin goes back to the original position after the patient throw the rubbish into the dustbin. The weight sensor and the infrared sensors collect and show the weight and the volume of the rubbish. Then the K60 SCMcan judge the condition to alarm the cleaning workers to clean and disinfect the dustbin.

By using optimal weighting algorithm and motion control algorithm for a particular track, the dustbin can tracking by the camera. The bluetooth modulecan achieve the reception of the button message. The design visual display interfacecan show the information of the weight and the volume of the rubbish.
\end{abstract}

\section{Introduction}

The dustbins in the hospital ward mostly are simple household dustbins which are lidless. The medical waste and household waste are long exposed in the flow of air, which is adverse to the patients' recovery. The motionless dustbins are unable to meet the needs of movement disorder patients.In the meantime, the dustbins always cannot be cleaned in time, which has bad influence to the environment of the ward.

To provide comfortable, cosy and healthy hospitalization environment for patient, I design this medical intelligent dustbin. This dustbin can reach the presupposed sickbed through the patient's instructions, which give convenience to the patients. In addition, it can avoid the accident of the seriously ill patients. When the waste in the dustbin is overweight or of huge size, the dustbin can make volume alarm to let the cleaning workers clean and disinfect the dustbin. This can saveresources and improve work efficiency, which has great medical prospects. Marketing this products to families and hospitals will be great.

\section{The Design of the Integrated System}

Functional Planning. This multifunctional dustbin can collect the waste in the hospitals and remind cleaners to clear and disinfect the dustbin. The functions of the dustbin are as follows:

The user can press the button to control the dustbin to move follow the presupposed routine. The dustbin can open its lid automatically and returns to the home position automatically.

The dustbin can collect the weight and the volume of the waste and show them.

When the waste in the dustbin is overweight or of huge size, the dustbin can remind the cleaning workers to clean and disinfect the dustbin.

The wholegraphplan of the system is as follows: 


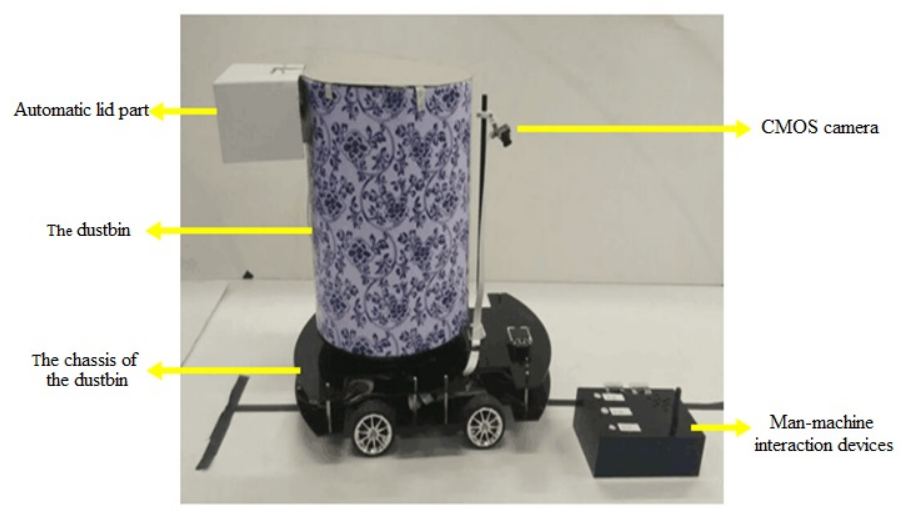

Fig.1 The wholegraphplan of the system

\section{Particular Design of the System}

Mechanical Structure Design. The Chassis of the Dustbin. The chassis of the dustbin is the main component of the system. It includes double acrylic plates. The battery, the pole to fix the camera and the motors are on the lower plate, the dustbin is on the upper plate. It is easy to install and the structure is stable. The lower plate is shown in Fig.2.

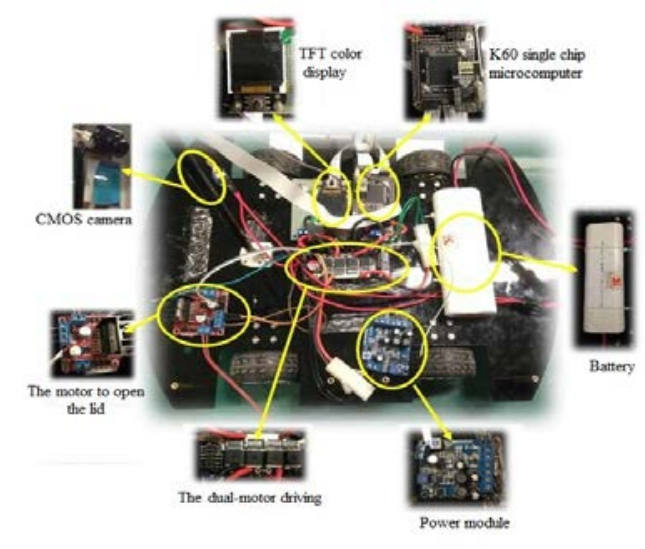

Fig.2the lower plate

Automatic Lid Part. The automatic lid part can open and close the lid by the four-bar linkage when the motor is run. The motor is controlled by the K60 SCM. The mechanical structure is shown in Fig.3.

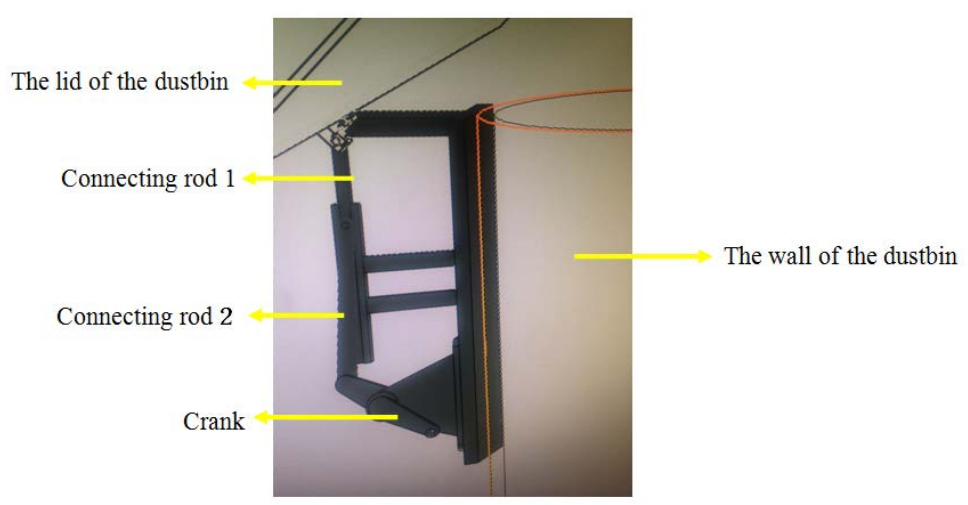

Fig.3 The mechanical structure of the lid

Hardware Circuit Design. The detection part of the waste's volume and weight. 
Three infrared sensors which are on the upper, middle and bottom wall of the dustbin, each of the sensors are into a 120 - degree. The sensors can detect the height of the waste in the dustbin. It is shown in Fig.4.

If the infrared sensors detect the waste, the sensor will create electric level and give it to K60 SCM. According to the level which is fed back by the three infrared sensors, the volume of the waste is detected.
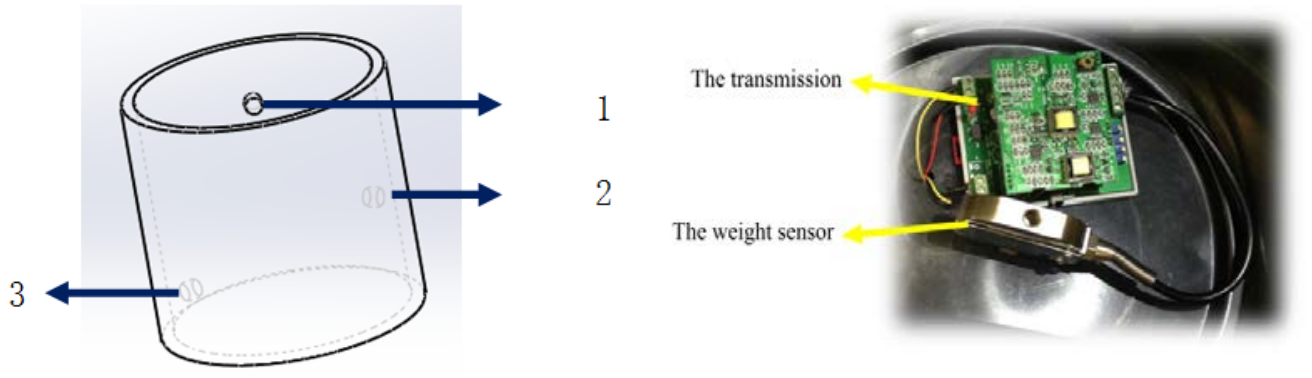

Fig.4The distribution sketch of the infrared sensorsFig.5Weight detection device

Use the weight sensor under the dustbin to measure the weight of the waste.Send small AC signal totransmitter, then the transmitter transmit the AC level to DC level and give it to the SCM. So the weight of the waste is measured. It is shown in Fig.5.

The Display Part of the Waste'S Volume and the Weight. In order to show the data which represents the volume of the waste, I design the display interface. The 1.44 inchesTFT color display is shown in Fig.6. Draw a rectangle which uses $(30,15)$ 、 $(64,15)$ 、 (30, 100)、（64, $100)$ as its vertices, and then divide the rectangle into three parts, partition off each parts via lines. The edge of the rectangle and the lines are white pixel lines, the width of them is 1 . The background is black. When the volume of the waste is $30 \%$ of the whole dustbin, only the bottom part of the rectangle displays for the green. When the volume of the waste is $60 \%$ of the whole dustbin, the bottom and the middle part of the rectangle displays for the green. When the volume of the waste is $90 \%$ of the whole dustbin, all parts of the rectangle displays for the green. So, the volume of the waste is easily visual. In addition, the display interface of the weight is shown in Fig.7.
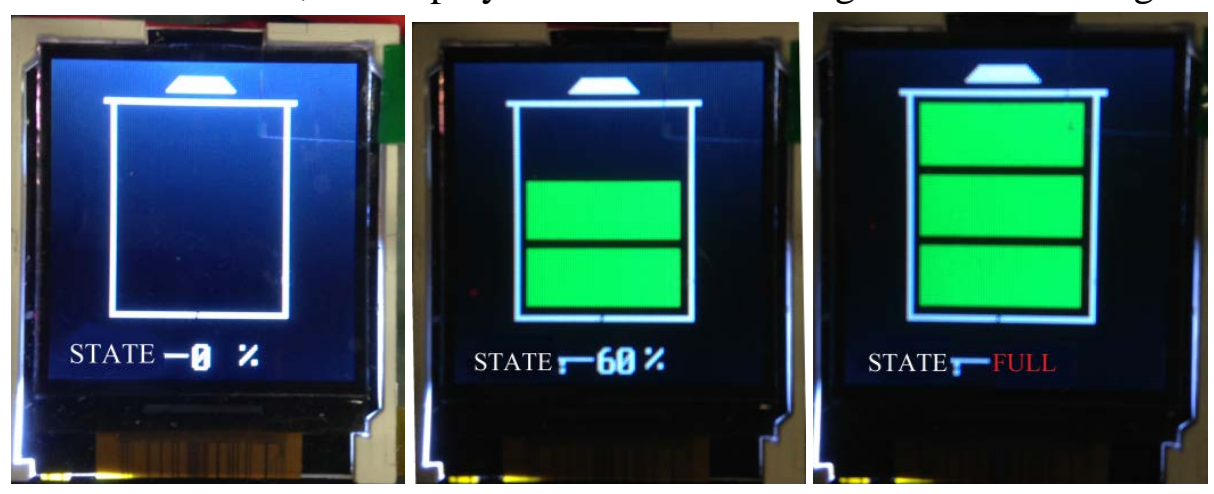

Fig.6Volumedisplay device
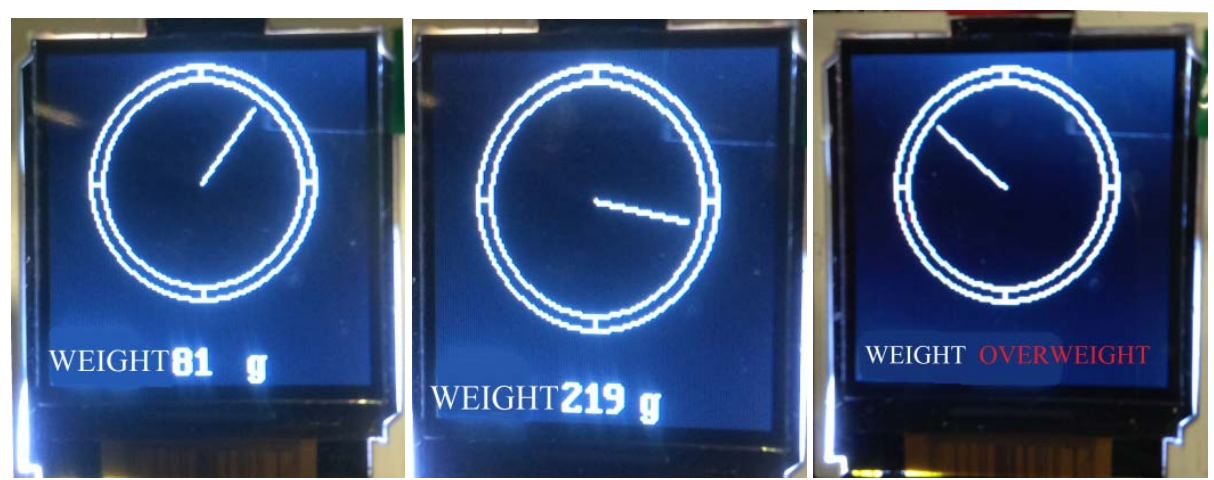

Fig.7Weight display device 
The Wireless Module and the Voice Module. Set three buttons to control the dustbin run along three routes and input the signal to K60 SCM.Use UARTwireless module to communicate. When press one of the buttons, the dustbin run along the presupposed route. When the weight or the volume of the waste is over the preset value, SCM will output a high-low level and the voice module will broadcast voice remind.These modules are shown in Fig.8.

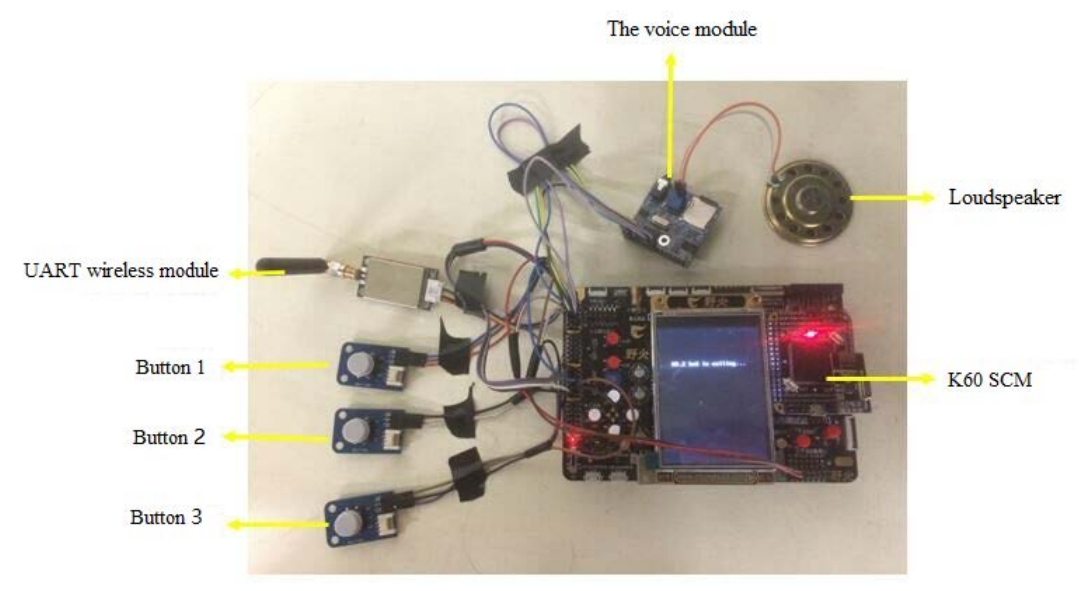

Fig.8The wireless module and the voice module

\section{Summary}

After debugging, this automatic dustbin can complete the following functions:

The dustbin can run along the presupposed routine, the accuracy is $100 \%$.

The dustbin can detect and display the volume and the weight of the dustbin.

The dustbin can remind the cleaners to clean the dustbin through the voice module.

\section{References}

[1] Zhang Hongyan, The automatic switch of trash can cover, Chinese Journal of Nosocomiology. 2005,15(5), 582-583; .

[2] WangZihui, Ye Yunyue, Research on Image Acquisition of the Self-tracing Car Based on CMOS Camera Sensor.Chinese Journal of Sensors and Actuators, 2009, 22(4), 484-487;

[3] Sun Baofa, Zhang Xiaoling, Hardware Design of Smartcar Tracking with Camera,Value Engineering. 2012,31 (30) ,201-202.

[4] Xiao Wenjian, LiYongke.Design of intelligent vehicle based on incremental PID contol algorithm.Information Technology, 2012(10),125-127 